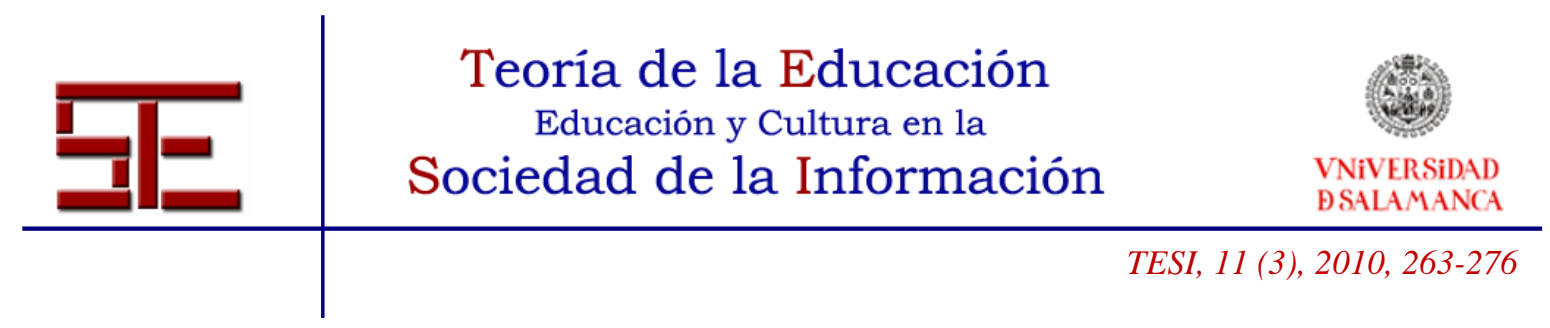

\title{
UNA NUEVA FORMA DE ENTENDER EL ROL EN SALAMANCA: PROYECTO MÍMESIS
}

Resumen: Los jugadores de rol suelen pertenecer a pequeños grupos con los que juegan. Normalmente estos grupos no cambian a lo largo de los años, existiendo reticencias a la hora de añadir nuevos miembros al grupo de juego. El Proyecto Mímesis nace en Salamanca en forma de asociación unificadora de jugadores, proponiendo actividades lúdico-culturales para todo el mundo rolero de la ciudad. Se pretende fomentar el universo de los juegos de rol, darlo a conocer y servir de plataforma y modelo para futuros proyectos relacionados con esta forma de ocio.

Palabras clave: juegos de rol; Salamanca; asociación

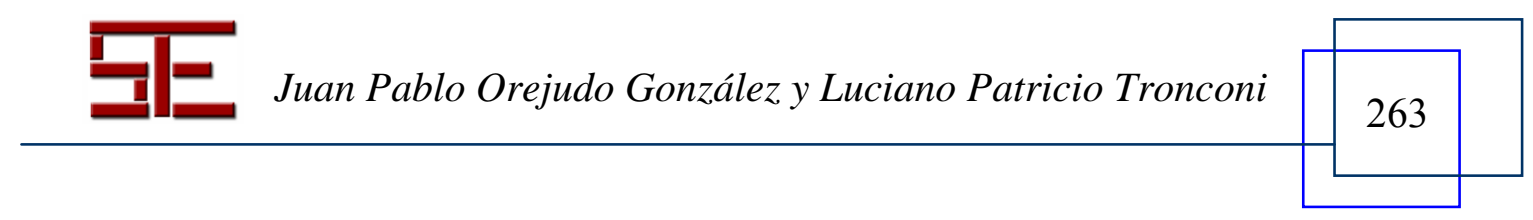




\section{A NEW WAY OF UNDERSTANDING THE ROLE IN SALAMANCA: PROYECTO MÍMESIS}

Abstract: The role players tend to belong to small groups with which they play. Usually these groups do not change over the years, there reluctance to add new members to the play group. Proyecto Mímesis was born in Salamanca unifying association of players, offering leisure and cultural activities for everyone in the city. It aims to promote the world of role-play, to publicize it and provide a platform and model for future projects related to this form of entertainment.

Key words: role-play; Salamanca; association.

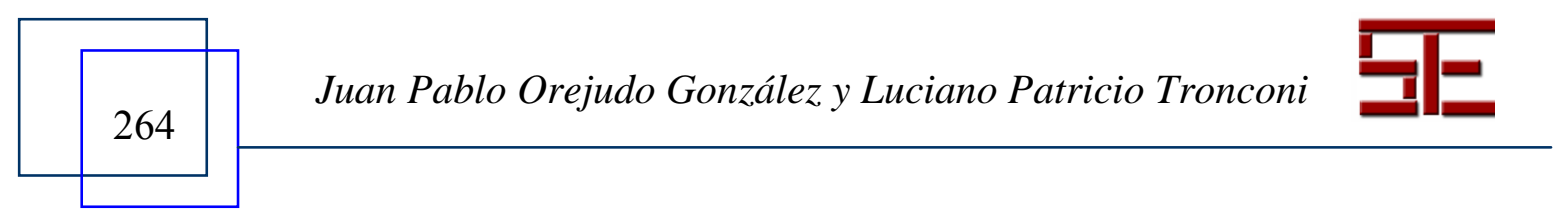




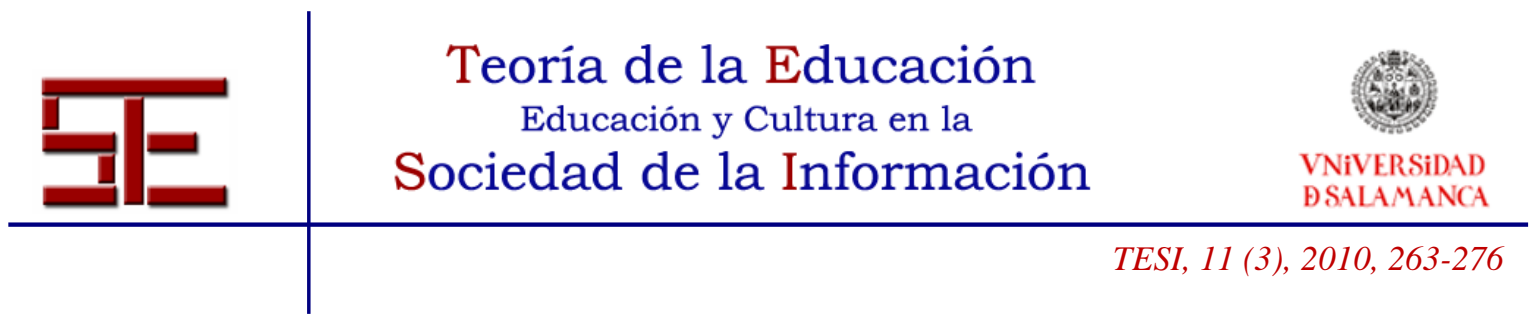

\title{
UNA NUEVA FORMA DE ENTENDER EL ROL EN SALAMANCA: PROYECTO MÍMESIS
}

Fecha de recepción: 07/06/2010; fecha de aceptación: 18/10/2010; fecha de publicación: 30/11/2010

\author{
Juan Pablo Orejudo González \\ juanpa_og@usal.es \\ Universidad de Salamanca \\ Luciano Patricio Tronconi \\ luchocthulhu@gmail.com \\ Universidad de Salamanca
}

\section{1.- INTRODUCCIÓN: PRESENTACIÓN Y BUENAS INTENCIONES}

En el siguiente escrito expondremos de la forma más clara y diáfana posible la línea que seguimos para la realización de nuestro propósito. El Proyecto Mímesis nace como experiencia piloto en la localidad de Salamanca a finales de 2008 con el fin de crear una agrupación de jóvenes roleros, la gran mayoría universitarios, con iniciativa y ánimo para la realización de actividades lúdico-culturales relacionadas con esta forma de ocio y otras similares. Salamanca -y gran cantidad de capitales españolas- está necesitada de un grupo que impulse la creación y organización de partidas de rol, tanto en vivo como en mesa, y lo fomente, sobre todo cuando hay mucha gente con ganas de jugar y aprender.

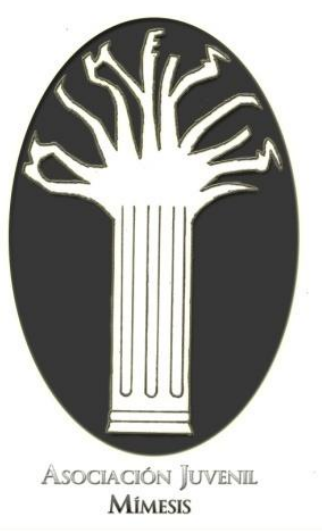

Durante el transcurso del año 2000 se formó en España la Asociación Nacional de Jugadores de Rol, Estrategia y Simulación Homo Ludens. Llenó el vacío existente en el panorama rolero dándonos voz a todos los jugadores que veíamos como en los medios de comunicación se nos satanizaba, acusándonos de crímenes horribles con los que no nos identificamos en absoluto. Finalmente esos crímenes se desvincularon del mundo del rol pero no se le dio importancia a esto. Se había añadido una gota más en el mar de

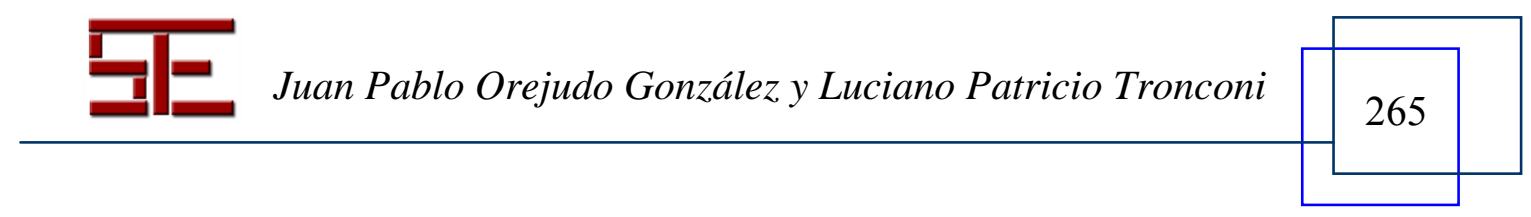




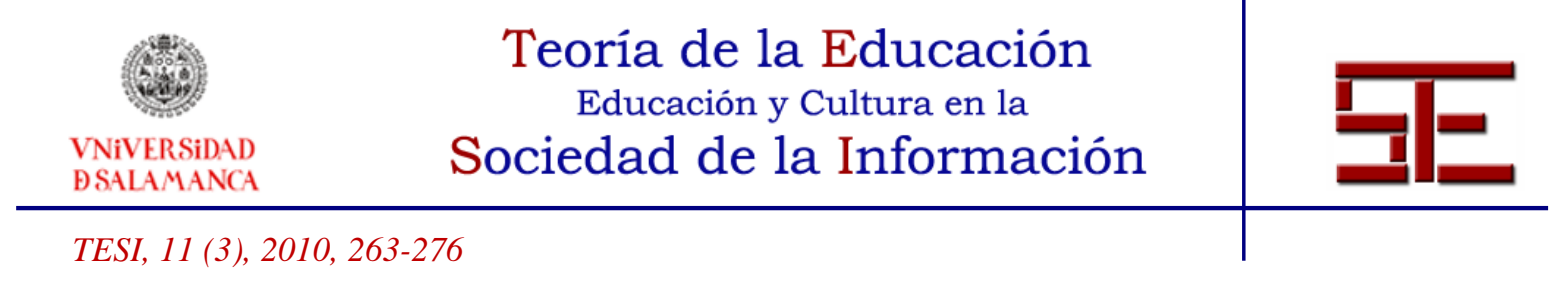

la leyenda negra de estos juegos y nadie había hecho nada para drenar el sobrante que no le corresponde en absoluto. Homo Ludens se disolvió en asamblea extraordinaria el día 17 de noviembre de 2007 y ese hueco vuelve al rol. Y regresa la necesidad, porque es una necesidad, de tener un camino que seguir y una voz para hablar y ser escuchados.

Sin tantas pretensiones de constituir una asociación de carácter nacional -aunque se volverá a replantear este asunto cuanto estemos en completo funcionamiento- hemos nacido para rellenar la carencia representativa existente en el mundo de los juegos de rol en la localidad de Salamanca.

Desde Salamanca se propone un modelo que al fin y al cabo es una alternativa que va más allá del ocio. Es un proyecto juvenil mediador entre intenciones y actos, que ayuda a poner en marcha proyectos y actividades que no serían capaces de organizarse por falta de apoyo y compromiso institucional.

También, queremos dar a entender que los juegos de rol no son dañinos por sí mismos sino que cualquier herramienta en manos equivocadas puede ser peligrosa.

\section{2.- OBJETIVOS}

El Proyecto Mímesis pretende aunar en sus objetivos gran parte de lo que creemos necesario para, por una parte, la comunidad rolera en sí y, por otra, la sociedad no familiarizada con el rol.

Principalmente surge con la mentalidad de dar un enfoque positivo y desmitificado de los juegos de rol, así como fomentarlos no solo como entretenimiento sino explorar todas sus posibilidades sociales y educativas.

Son objetivos prioritarios de esta Asociación:

1) La realización de actividades lúdico-culturales. Las más importantes serán explicadas en el epígrafe 3 .

2) La promoción de la cultura y del arte. Seremos partícipes en la organización y colaboración de lecturas literarias y poéticas, exposiciones fotográficas, etc.

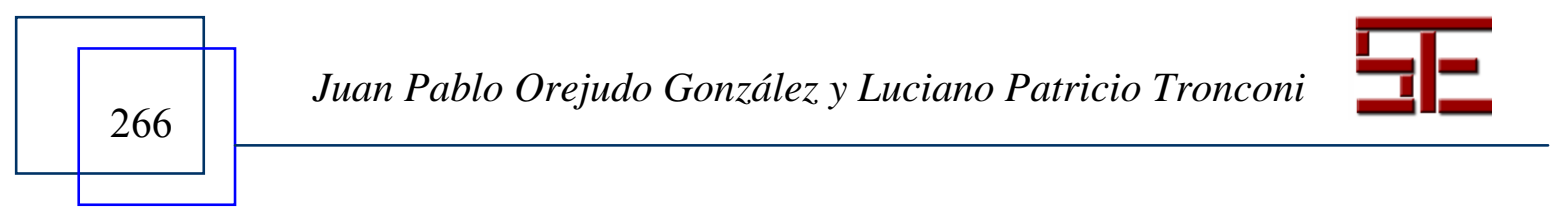




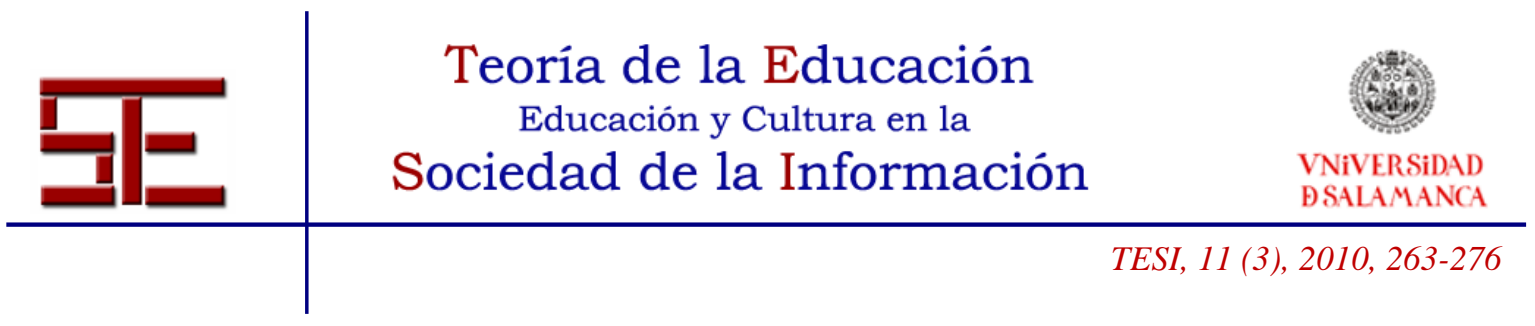

Intentaremos abarcar el máximo espectro cultural dentro de nuestras posibilidades en la localidad.

3) El fomento de creatividad e interacción social entre grupos juveniles. Ayudaremos a impulsar el diálogo entre el gran número existente de agrupaciones juveniles salmantinas y organizaremos proyectos en común siempre y cuando no entren en conflicto con los objetivos de los grupos participantes.

4) Formar grupos teatrales y de ámbito interpretativo. Será explicado a lo largo del punto 3.2.5.

5) El fomento de la creación y promoción de grupos musicales junto con la cultura musical. Este punto va de la mano con la promoción del arte y la cultura pero se ha decidido su posición individual por la diferente organización y tratamiento del tema. La música forma parte de la cultura y el arte actual, y nosotros queremos dar la oportunidad a grupos nóveles mediante la organización de eventos musicales pequeños para dar a conocer su música en la localidad. También se encuentra relacionado con el proyecto de la creación de un podcast, que explicaremos más adelante en el epígrafe 3.2.4.

6) La creación de publicaciones cuya temática incluya los ámbitos que conciernen a dicha asociación. Este apartado será ampliamente explicado más adelante en el punto 3.2.1.

7) Realización de actividades de esparcimiento siempre y cuando se encuentren dentro de los objetivos de la asociación.

\section{3.- METODOLOGÍA: PROYECTOS Y ACTIVIDADES}

Para el cumplimiento de los fines anteriormente citados se realizarán las siguientes actividades. Éstas se encuentran dividas en dos grupos temáticos: actividades de carácter lúdico y actividades de carácter cultural. Cabe destacar que la gran mayoría de las actividades se encuentran interconectadas entre sí, creando un colectivo unificado.

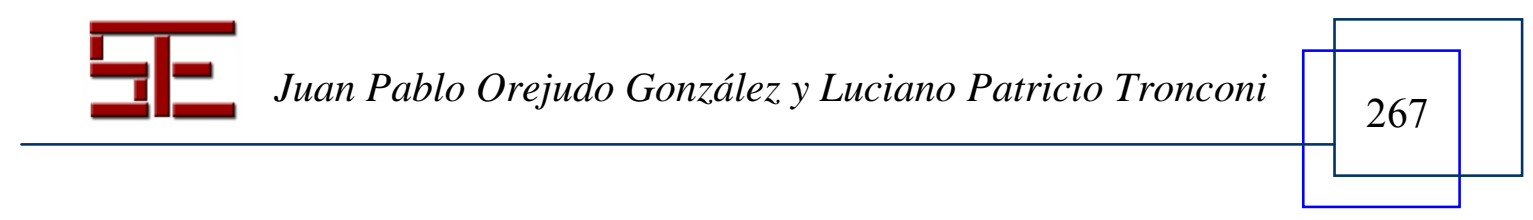




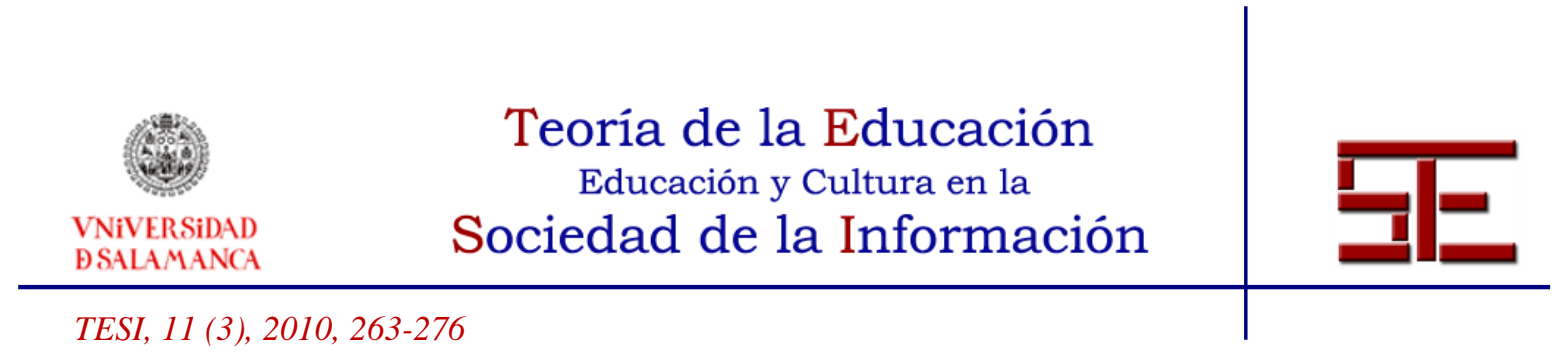

\subsection{Lúdicas}

Como lugar de encuentro y asociación sin ánimo de lucro, las actividades lúdicas tienen un gran peso dentro del Proyecto Mímesis. Con esto, queremos unir a toda la comunidad rolera salmantina y proporcionarle actividades y un lugar en el que poder entretenerse con estos juegos.

\subsubsection{Organización de juegos de rol}

Se organizarán partidas de juegos relacionados con el rol y la estrategia, usando para ello todas las localizaciones posibles y las comodidades de las que podamos disponer. Normalmente los jugadores de rol se encuentran configurados en grupos pequeños de amigos, soliendo jugar entre ellos mismos, ya sea por cierre de grupo frente a nuevos jugadores o aclimatación de la forma de juego de los ya conocidos. Nosotros organizaremos partidas sin tener en cuenta este aspecto grupal de amigos, pudiendo ofrecer la oportunidad de conocer jugadores e, incluso, darle la oportunidad a los jugadores neófitos de poder interactuar con los juegos de rol. Además, nos encargaremos de arbitrar neutralmente durante el transcurso de los juegos.

Para poder llevar a cabo este punto hemos puesto a disposición de todo el mundo una solicitud en nuestra página web. Al cumplimentar la solicitud de actividad y entregarla al coordinador indicado se empezará con la realización de dicha actividad- este aspecto será explicado más adelante-. No obstante, se realizarán y organizarán numerosas partidas motu proprio desde la asociación sin tener que realizar ningún tipo de petición.

\subsubsection{Organización de jornadas lúdicas}

La organización de jornadas lúdicas es una manera de fomentar la participación en común de muchos amantes de los juegos de rol. Además, es una estupenda oportunidad para aquellos interesados en conocer estas dinámicas, pues si bien el fenómeno de los juegos de rol es reducido en comparación con otros, existe una aceptable variedad en el mercado.

Pero no sólo tienen cabida los juegos de rol en unas jornadas. No se excluyen formas de ocio como juegos de mesa, juegos de carta, juegos de miniaturas, softcombat y otros tantos juegos que no son ajenos al rol. En unas jornadas además de poner en contacto a los diferentes aficionados entre sí, se abre la oportunidad de presentar los nuevos

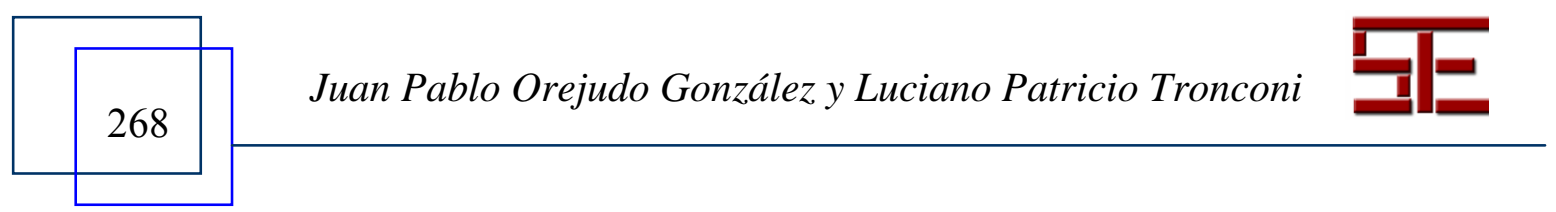




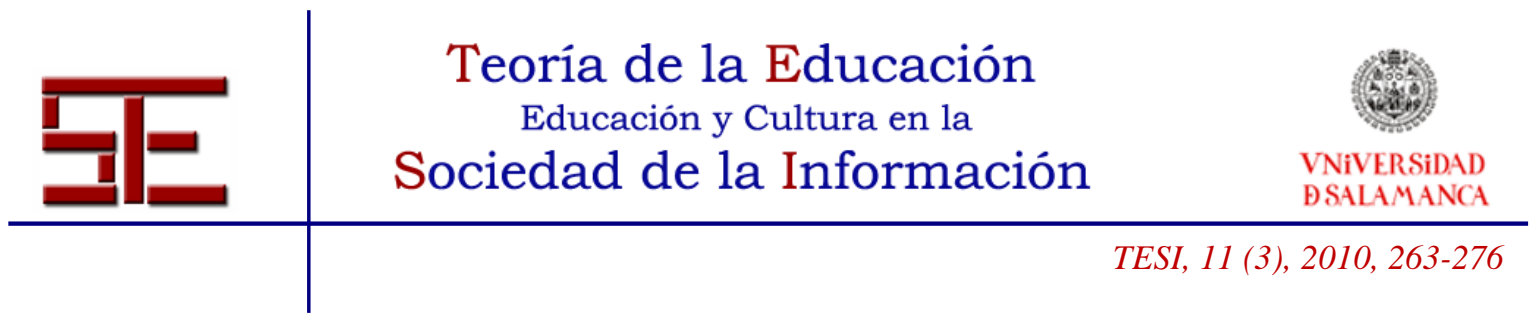

productos editoriales, organizar torneos, conferencias de expertos del sector, presentaciones o exposiciones; logrando así fomentar siempre un comportamiento comunitario y entretenido entre los asistentes.

La periodicidad de las jornadas será trimestral para aquellas de carácter modestamente pequeño; y una jornada anual que agrupará a las localidades adyacentes.

\section{$\underline{\text { 3.1.3 Organización de otras actividades lúdicas alternativas }}$}

Presentamos bajo este epígrafe la puesta en punto de partidas o reuniones para celebrar otro tipo de juegos o formas de esparcimientos de amplia gama pero siempre familiares a los roleros. Muchos juegos de mesas, juegos de miniaturas o juegos de cartas están emparentados culturalmente con los juegos de rol. Se propone realizar torneos o simples reuniones para acercarnos a muchas maneras de entretenimiento de las ya mencionadas fuera de las jornadas propiamente dichas.

La asociación está abierta a cualquier proposición por parte de cualquiera de sus miembros para organizar alguna actividad divertida sin tener por qué estar relacionada con todos los epígrafes anteriores, siempre y cuando la idea tenga el visto bueno de los mismos miembros.

\subsection{Culturales}

Los juegos de rol se encuentran ampliamente vinculados a ciertos aspectos culturales: son juegos basados en libros que hay que leer y aprender e ilustrados con dibujos profesionales de gran carácter estético. No sólo queremos fomentar la lectura y las bellas artes sino ampliar los márgenes para que todos puedan expresarse de la forma que mejor puedan. Intentaremos abrir puertas y explorar horizontes culturales dentro de la localidad, acercando todo este contenido a las personas interesadas e intercambiando conocimientos desde diferentes enfoques en diferentes formatos.

\subsubsection{Revista}

Se realizará una revista de temática libre, teniendo prioridad la cultura y el arte, sin adscribirse a ninguna política, corriente de pensamiento o filosofía, sino sólo a la libertad de expresión de cada uno de sus colaboradores y a la justa reivindicación de la cultura, el arte y cualquier otra inquietud de sus colaboradores. La revista estará abierta

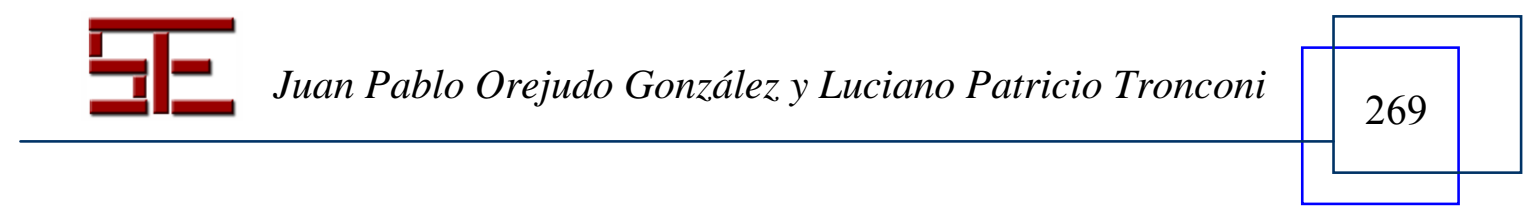




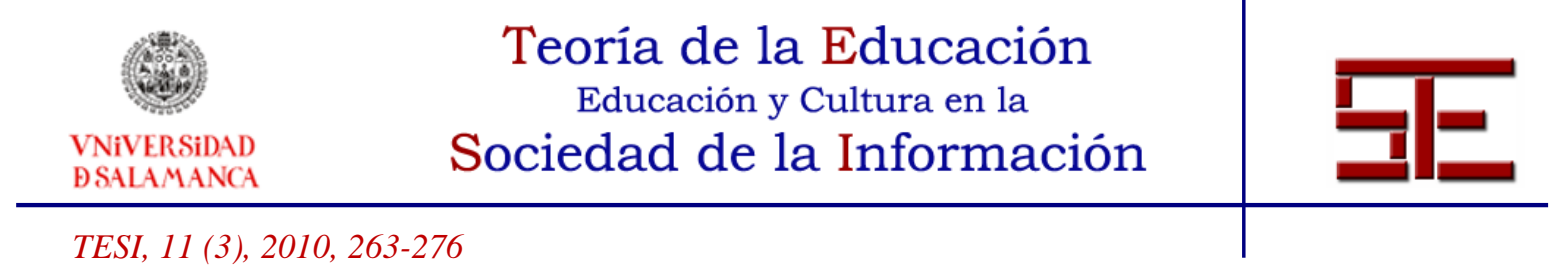

ante la participación de cualquier interesado, aceptando colaboraciones externas e internas desde la propia asociación, en especial, los miembros del club literario, del que se hace mención en el siguiente epígrafe, pues serán los que compongan el pilar en el que se sostendrá la publicación.

Será posible este proyecto gracias al dinero destinado desde la propia asociación, el sustento publicitario añadido desde distintos establecimientos, editoriales y demás posibles patrocinadores.

Se compondrá de varios artículos de temática diversa: monográficos, críticas, entrevistas y presentaciones de varias noticias. Por otra parte, será importante el espacio dedicado a ilustración, tiras cómicas, relatos breves, poesía o cualquier otro tipo de manifestación artística literaria. También tendrá cabida un calendario de actividades lúdico-culturales de interés que se realicen en la ciudad de Salamanca.

La vía de publicación será electrónica. La edición electrónica facilitará la llegada a lectores de cualquier sitio, además de permitir utilizar herramientas audiovisuales para el apoyo y complemento de la publicación, relacionándose así con el epígrafe 3.3.

\subsubsection{Club literario}

Bien sabido es que los aficionados a los juegos de rol forman un grupo potencialmente lector (Sevillano Pareja, 2009). Por ello se creará un club literario dinámico e innovador, donde se desarrolle no sólo un hábito de lectura compartida y la elaboración del comentario del texto oral entre los participantes, sino que se intentará ir un paso más allá. La asociación propone para tal, lecturas de calidad, en lo posible relacionadas con las muchas y variadas temáticas que son más cercanas a los juegos de rol, que estén abiertos a la posibilidad de una puesta en marcha de actividades lúdico-culturales de todo calibre y no necesariamente literarias excluyentes. De esta manera, no es ilícito pensar en eventos que puedan ir desde el debate hasta la exploración de las relaciones entre cine y literatura, literatura y juegos de rol o de mesa, literatura y música, recitales de poesía, certamen de relato breve y otras ideas que puedan surgir entre los miembros y sean igualmente válidas sin importar lo descabellada que pueda ser dicha propuesta siempre y cuando esté lógicamente argumentada.

Los participantes en este club son también los colaboradores más directos de la revista de la asociación, mencionada en el epígrafe anterior. En ella podrán reflejar las

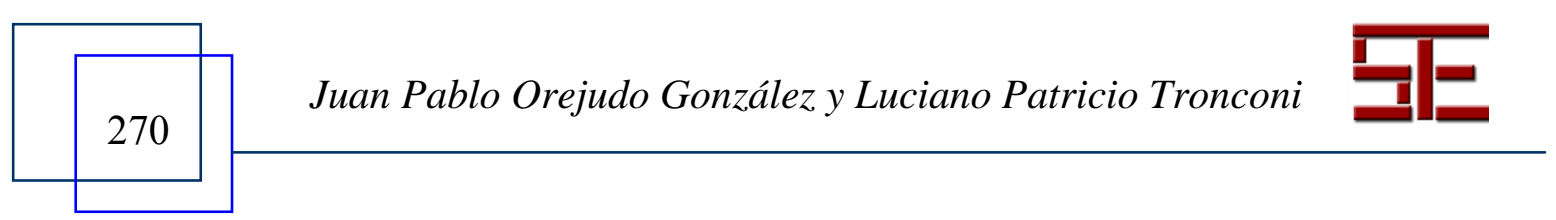




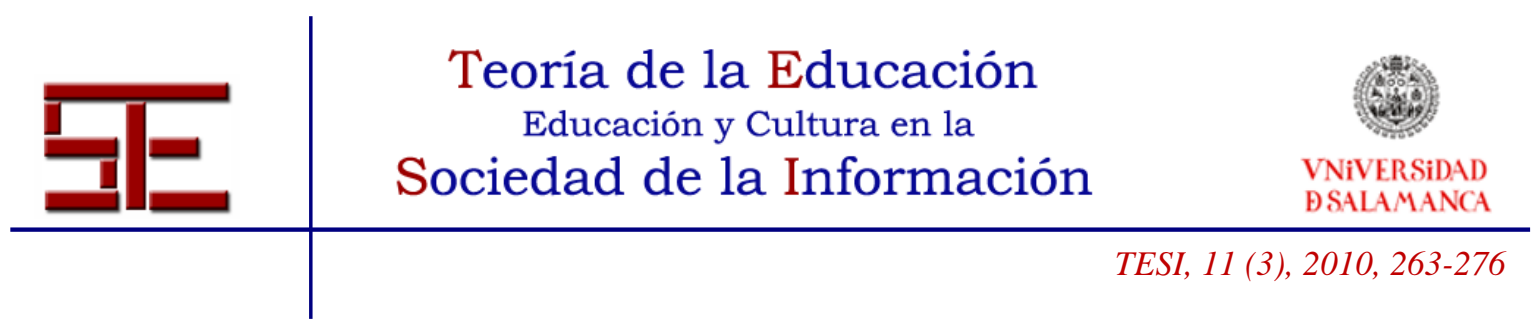

conclusiones de sus investigaciones y aprendizajes recibidos en las distintas actividades del club literario.

\subsubsection{Creación de una biblioteca especializada}

Son pocas las bibliotecas públicas -incluso de ámbito nacional- que cuentan en su catálogo con elementos referidos a los juegos de rol en número representativo y en concordancia con lo existente en el mercado. El trabajo de investigación de Héctor Sevillano Pareja (2008) ha dejado claro que existe suficiente material editorial perteneciente a este ocio alternativo como para contar con una representación más elevada en nuestros estantes municipales. La biblioteca pública de la Casa de las Conchas de Salamanca cuenta en su catálogo con diez manuales de juego de rol, todos ellos anteriores a 1995 con lo que, aun no quedándose totalmente obsoletos, se encuentran en un segundo plano en elección al no recibir actualizaciones de material y tener la casi ineludible necesidad de utilizar la última edición del juego para su utilización. En contraposición, la biblioteca de la Fundación Germán Sánchez Ruipérez de Salamanca cuenta en sus estanterías con manuales de últimas ediciones de uso repetido y común. El problema es que el número de ellos, como en el anterior caso, escasea. Por otra parte, los roleros suelen poseen en su casa una biblioteca personal bastante abultada, y no cae en saco roto pues el material es compartido y danza entre el grupo de amigos, amortizando el dinero que cuesta uno de los libros básicos o ampliación de los mismos.

Lo que pretendemos desde la Asociación Mímesis es la creación de una biblioteca con material escrito y audiovisual para su posterior uso entre los miembros de la asociación mediante consulta y préstamo. Con esta iniciativa podremos crear un fondo compuesto de manuales, artículos y cualquier otro escrito referido a los juegos de rol para poder conseguir una mayor recopilación de información sobre este ocio. No nos olvidamos tampoco del aspecto musical compuesto por, generalmente, bandas sonoras instrumentales en formato físico (CD) y electrónico para la mejor ambientación a la hora de contar historias e interpretar las partidas alrededor de la mesa.

La biblioteca, que ya cuenta con varios ejemplares de ediciones nuevas de los últimos manuales en el mercado, tiene la intención de empezar siendo un proyecto privativo favoreciendo a los miembros de la asociación. Este último punto se verá modificado una vez el número de ejemplares que poseamos supere al de cualquier biblioteca de la

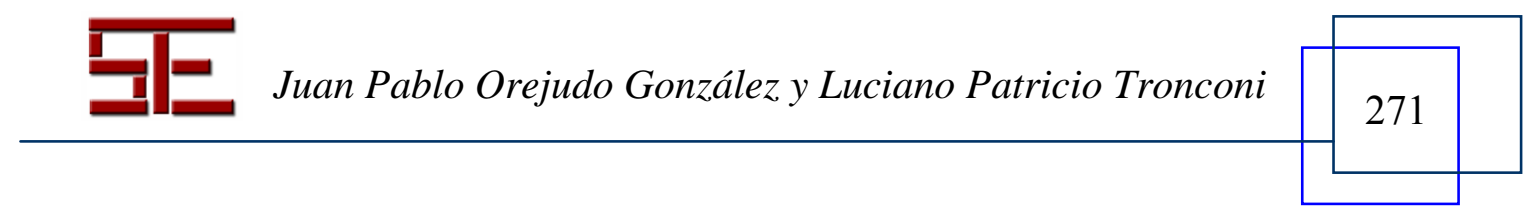




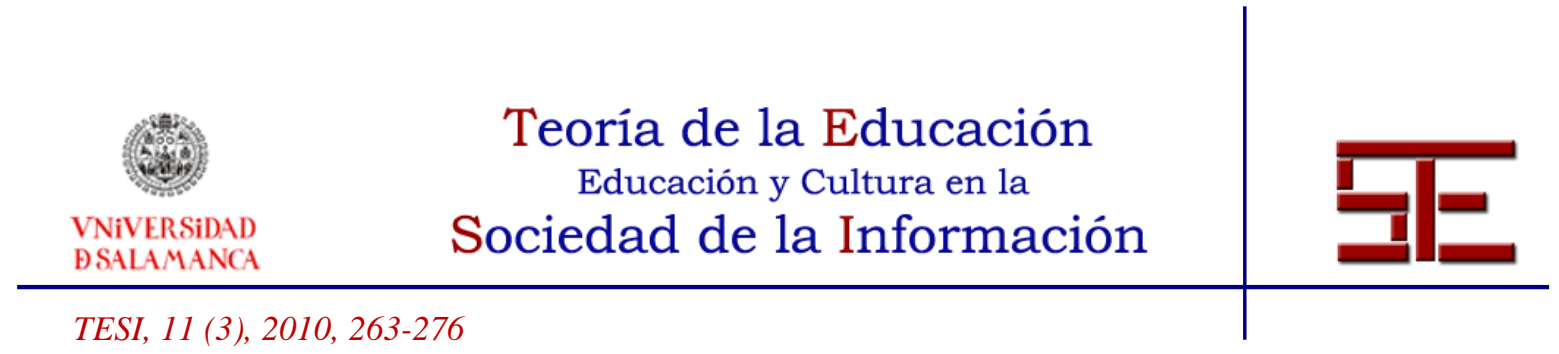

provincia -empresa de por sí nada difícil pero muy importante- pudiendo ser consultados desde dicho momento por cualquier persona interesada.

\subsubsection{Podcast y Programa radiofónico}

Esta actividad se encuentra inseparablemente ligada a la interacción con otros grupos juveniles de la localidad salmantina, la creación de una revista, así como del proyecto de la creación de una página web para su posterior publicación en red.

Junto con la revista explicada anteriormente, ésta será una de las formas utilizadas por Mímesis para informar sobre todas sus actividades presentes, sus resultados pasados y sus proyectos futuros. Este proyecto se centrará en proporcionar información referente a los juegos de rol. Por tanto, tendrá estructura informativa. Aun así, constará de varias secciones entre las que se encuentran entrevistas con organizadores de actividades relacionadas con ocio alternativo o personas del mundo rolero, actividades futuras de Mímesis y críticas de los productos en el mercado. Tendrá carácter mensual debido al leve goteo de novedades en el sector. Además, teniendo una visión no excluyente, el programa radiofónico ofrecerá un breve espacio musical para grupos nóveles.

Está prevista la emisión del primer programa a finales del primer cuatrimestre del curso académico 09/10 (noviembre-diciembre) dentro de la parrilla radiofónica de Radio Universidad, radio perteneciente a la Universidad de Salamanca.

\section{$\underline{3.2 .5 \text { Grupo de teatro }}$}

Los juegos de rol tienen su origen en los psicodramas de los años 60. Representar una situación, intentar ponerse en la piel de otro y actuar en consecuencia no es sólo propio de los juegos de rol. La escuela de interpretación Stanislavski de inmersión se basa también en este aspecto y a nada se parece más el rol en vivo que a un teatro improvisado. No es descabellado entonces suponer que a muchos roleros les pueda interesar el hermano mayor de los juegos de rol: el teatro.

Se propone la creación de un grupo de teatro a nivel local que pueda participar de la escena salmantina junto a otros grupos teatrales de la misma. También pretendemos explorar y potenciar las herramientas que tienen en común los juegos de rol y la interpretación teatral. Los juegos de rol y el teatro tienen substanciales conexiones. Ambos se basan en el juego interpretativo de un rol. El teatro es usado socialmente para

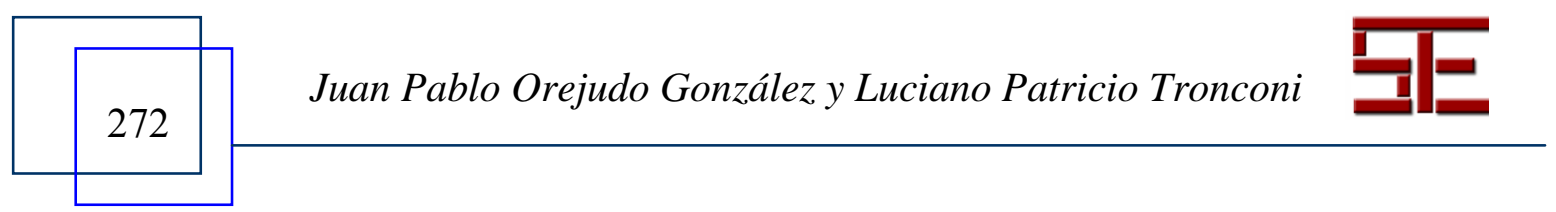




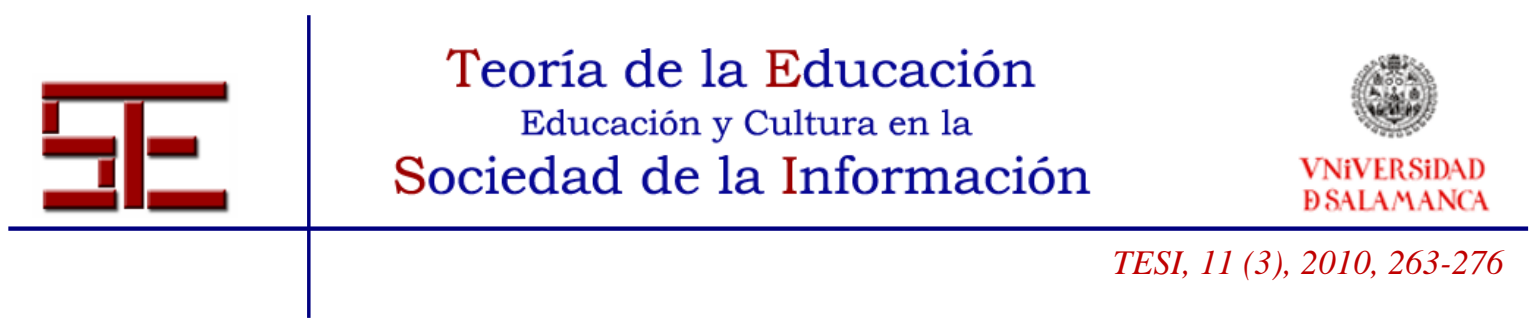

el entretenimiento de un público observador mientras que el juego de rol sirve para el entretenimiento de las personas que interactúan dentro de la propia interpretación. Por eso intentaremos impulsar ambos aspectos interpretativos a través de Mímesis.

\subsubsection{Otras colaboraciones culturales}

El Proyecto Mímesis goza desde sus fines estatuarios de El fomento de creatividad e interacción social entre grupos juveniles. Este aspecto es destacable porque deja la puerta abierta a futuros proyectos colaborativos entre entidades culturales y juveniles. Ya se está poniendo en marcha el diálogo entre asociaciones para la actuación conjunta en diversas actividades. Un ejemplo de ello es la anteriormente citada creación de un podcast mediante la colaboración entre diversas radios locales y el Proyecto Mímesis.

Además, Mímesis colaboró en el II Congreso Nacional sobre naturaleza, evolución, límites y posibilidades de los juegos de rol, efectuado durante los días 4, 5 y 6 de mayo de 2009 y organizado por la Universidad de Salamanca. Su función en el congreso estuvo vinculada al apoyo coordinativo y organizativo a la par que informativo para todos los asistentes. Varios miembros del Proyecto estuvieron a cargo de la organización en función de coordinadores para cualquier necesidad que surgiera durante su ejecución. Además, se entregó a todos los asistentes una encuesta, diseñada por la asociación, para la evaluación de la calidad del congreso, sirviendo también para la conjunción de proposiciones y estudio de futuros proyectos educativos partícipes en la Universidad de Salamanca.

También, Mímesis se encargará de la organización y de la puesta en marcha de charlas informativas mensuales en el entorno universitario sobre los aspectos básicos de los juegos de rol. Con esta propuesta tenemos la intención de informar y acercar esta forma de ocio para que, a puerta abierta, quien quiera, pueda tener la oportunidad de recibir ciertos conocimientos sobre estos juegos y sus posibles aplicaciones.

\subsection{Multimedia}

Este apartado engloba todo lo relacionado con el papel que desempeñarán las TIC en este ambicioso proyecto. Cada día es menos necesaria la presencia física en los encuentros comunicativos entre personas, viéndose suplida esta necesidad con las nuevas tecnologías forales, usadas ya, por ejemplo, en gran número de universidades españolas para complementar las explicaciones en el aula.

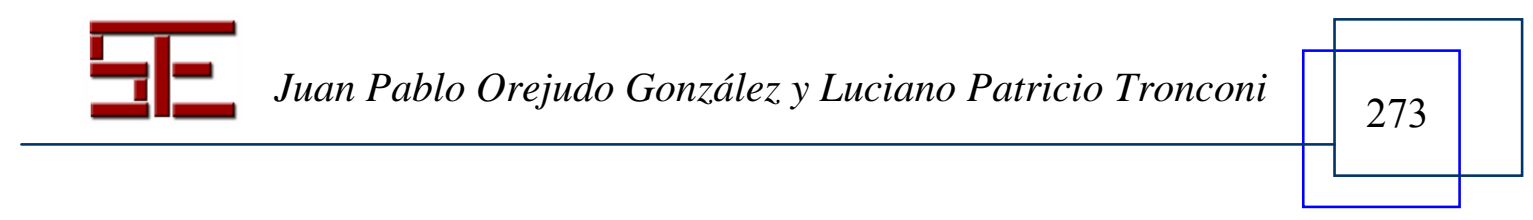




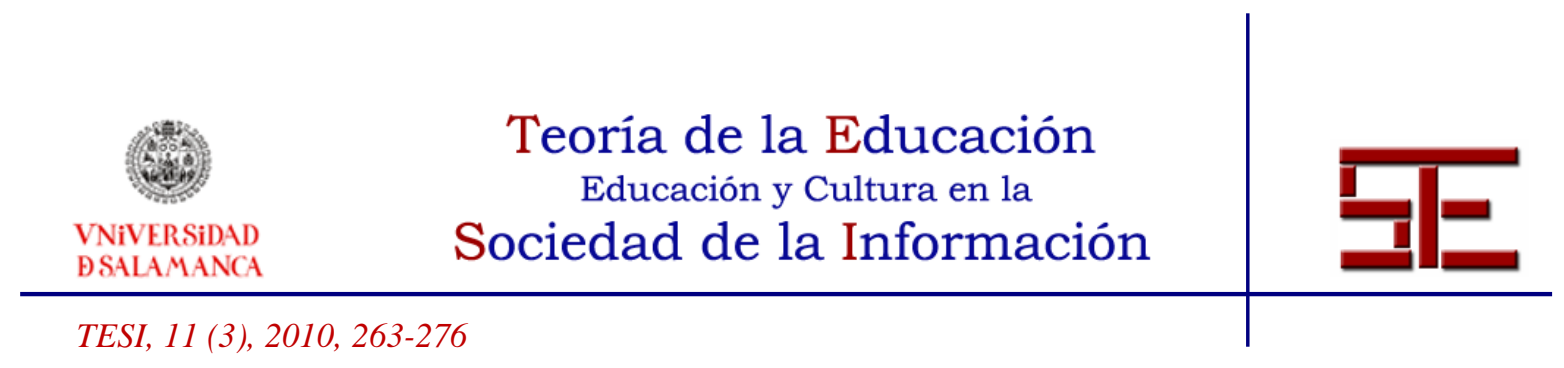

\subsubsection{Página web}

Hoy en día la manera más rápida de llegar a mucha gente en todo el mundo es a través de Internet. Por este motivo, la asociación tendrá una página web donde ir anunciando, mediante un calendario ordenado y actualizado, las novedades del sector como los nuevos eventos que se organicen, o noticias de interés en la evolución de la asociación. Servirá como un punto de información continuo donde sólo los miembros, mediante cuentas personales, podrán consultar el estado de la biblioteca, el saldo monetario del tesoro, las actas de las juntas, etc. También existirá a disposición pública información general de la asociación y noticias relacionadas.

La página electrónica servirá de apoyo y plataforma para todas las distintas actividades de la asociación que la requieran, tales como el podcast o la revista en su formato electrónico.

Esta página web será complementada además por un foro, del que se hace mención en el punto siguiente, y una cuenta de correo electrónico para dirigirse a la junta.

Tanto la página web como el foro se encontrarán alojados por el servidor de la Universidad de Salamanca.

\subsubsection{Comunicación grupal mediante foro}

El foro ha sido constituido como un lugar multidisciplinar. Ocupa el lugar básico de comunicación y encuentro entre los miembros y toda persona interesada en el tema que tratamos. Tendrá autonomía dentro de Mímesis, pudiendo ser moderado por personas ajenas a la asociación pero con intereses comunes. Será posible una comunicación abierta, libre, democrática y sin censura pues no se encuentra, ni se encontrará, vinculado a ninguna ideología, ya sea política o comercial.

Tendrá la función de notificar cualquier información referente a la cultura, videojuegos, música, cine, teatro y juegos de rol. Cada persona tendrá la oportunidad de intervenir en los temas dando su opinión y creando un diálogo basado en intercambio de ideas. Además será el lugar para dar a conocer la preparación de encuentros y surgimiento de partidas futuras. También habrá lugar para una zona de interés común pedagógico en el que se discutirán los últimos avances investigativos en lo referente a los juegos de rol.

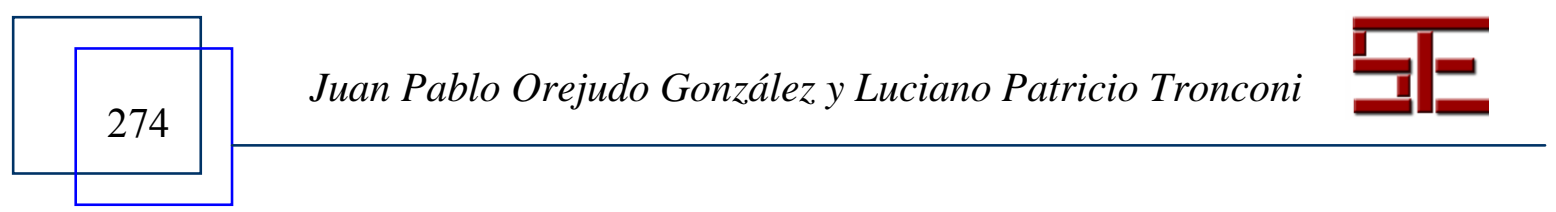




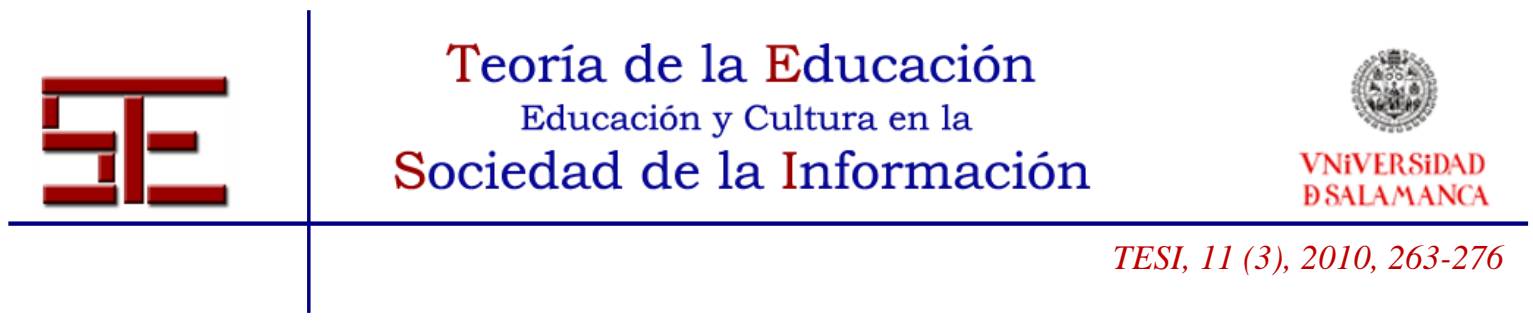

\section{4.- FASES DE IMPLANTACIÓN DEL PROYECTO}

No todas las actividades anteriormente explicadas se encuentran en funcionamiento pleno a día de hoy. La organización de juegos de rol, la organización de jornadas lúdicas y actividades lúdicas alternativas, la creación de una biblioteca y la creación de un foro ya se encuentran activas y a disposición de los miembros. El resto de proyectos se encuentran en fase de creación, implicando a todos los estratos del proyecto, teniendo intención de estar totalmente implantados coincidiendo con el inicio del curso académico 2009/2010.

\section{5.- FUNCIONAMIENTO INTERNO}

Mímesis es una organización no lucrativa con orden jerárquico en sus obligaciones. Para participar de Mímesis hay que pagar una pequeña cuota trimestral -excepto en verano-.

Existen tres categorías de socios:

- Socios fundadores: socios que han fundado Mímesis.

- Socios numerarios: aquellos socios no fundadores menores de 30 años.

- Socios honorarios: aquellos socios mayores de 30 años. En un principio no se contemplaba esta posibilidad pero, dada la acogida de la asociación entre mayores de 30 años pertenecientes a tercer ciclo universitario y doctores, nos vimos en la tesitura de crear esta categoría para poder contar con ellos.

Para su mejor funcionamiento, la organización jerárquica se ha dividido en tres grandes grupos:

- Junta Directiva: formada por el Presidente, Vicepresidente, Secretario, Tesorero y dos Vocales. Es el órgano administrativo y de toma de decisiones. Se encarga de los trámites burocráticos y debate sobre la ejecución de nuevas actividades.

Las reuniones de la Junta Directiva tienen carácter abierto y pueden estar presentes todos los miembros de Mímesis que lo deseen. Los miembros tienen voz pero no voto, siendo los vocales las personas seleccionadas para transmitir sus opiniones y proporcionarles voto.

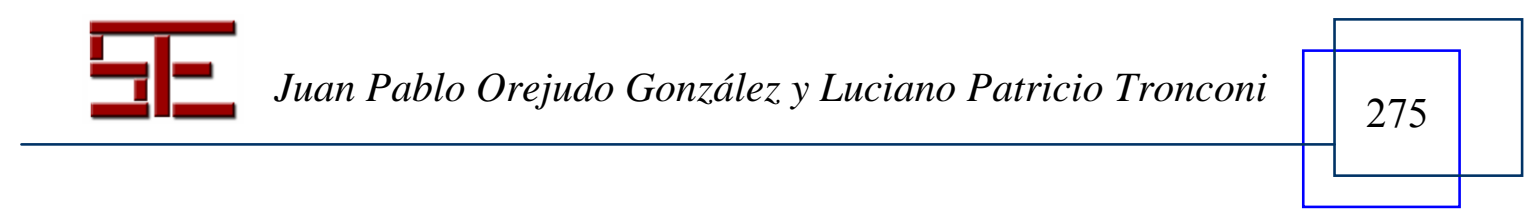




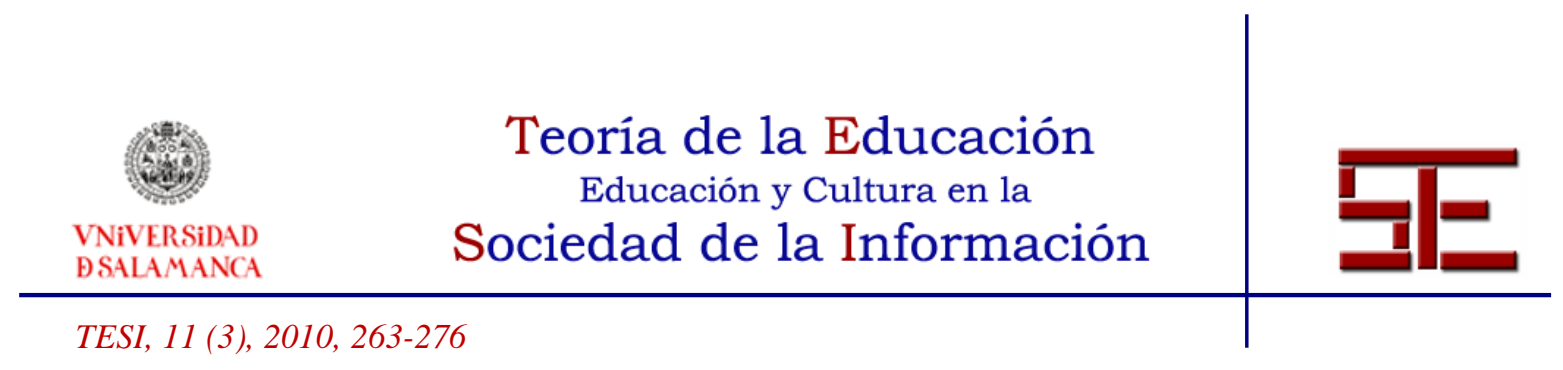

- Coordinadores: este grupo está formado por Coordinador de Juegos de Rol, Coordinador de Mesa y Estrategia, Coordinador de Cultura, Coordinador de Multimedia. Algunos cargos son compartidos debido a su complejidad a la hora de llevarlo a cabo. Son los encargados de transmitir las propuestas de actividades a la Junta Directiva para su posterior debate. Cada coordinador se encarga de regular todos aquellos aspectos referentes a su puesto. Tienen responsabilidad última de los delegados y responden de sus acciones.

- Delegados: grupo formado por los organizadores de actividades pertenecientes a los miembros numerarios de Mímesis. Presentan sus propuestas de actividad al coordinador correspondiente y si es aprobada será Delegado para llevarla a cabo, siempre con ayuda de su coordinador.

\section{6.- BIBLIOGRAFÍA}

Aristóteles (2008). Poética. Madrid: Alianza Editorial.

Huizinga, J. (2002). Homo Ludens. Madrid: Alianza Editorial.

Sevillano Pareja, H. (2009). Estudio del sector editorial de los juegos de rol en España. Tesis Doctoral. Salamanca: Ediciones Universidad de Salamanca.

Tizón, R. (2007). Creer lo increíble: verdades y mentiras sobre los juegos de rol. Madrid: NoSoloRol.

Para citar el presente artículo puede utilizar la siguiente referencia:

Orejudo González, J.P. y Tronconi, L. P. (2010): Una nueva forma de entender el rol en salamanca: proyecto Mímesis, en Orejudo González, J.P. (Coord.) Perspectiva educativa y cultural de "juego de rol". Revista Teoría de la Educación: Educación y Cultura en la Sociedad de la Información. Vol. 11, no 3. Universidad de Salamanca, pp. 263-276 [Fecha de consulta: dd/mm/aaaa].

http://campus.usal.es/ revistas_trabajo/index.php/revistatesi/article/view/7488/7508

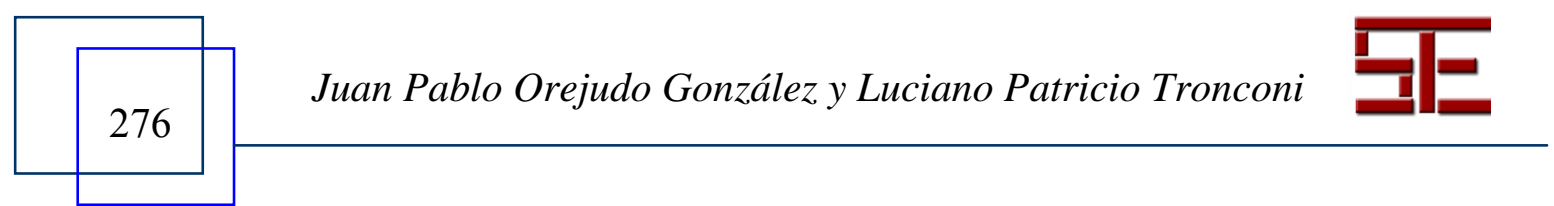

